\title{
TRABALHO DOCENTE: FORMAÇÃO E DESENVOLVIMENTO DA IDENTIDADE DO PROFESSOR DE MATEMÁTICA
}

\author{
Bruno Silva Silvestre ${ }^{1}$
}

\begin{abstract}
RESUMO: O presente ensaio discute o trabalho docente do professor de matemática em uma perspectiva histórico-cultural no movimento formativo da construção da identidade e da profissionalização desse professor. Constituído por meio de estudos teóricos, tem-se como objetivo elucidar as possíveis relações que podem ser observadas entre o trabalho docente e a construção da identidade do professor de matemática na proposta de apresentar algumas determinações sobre o trabalho - em uma perspectiva marxiana - trabalho docente, identidade e formação em movimento do professor de matemática. O texto apresenta uma análise com elementos do método histórico-dialético que indicam possíveis relações entre o profissional e a formação continuada que contribuem para a constituição da identidade docente do sujeito que ensina e organiza o conhecimento escolar em matemática por meio de sua atividade principal.
\end{abstract}

Palavras-chave: Trabalho Docente. Formação em Movimento. Identidade Profissional. Professor de Matemática.

\section{TEACHING WORK: FORMATION AND CONSTRUCTION OF THE IDENTITY OF THE MATHEMATICS TEACHER}

ABSTRACT: The present essay discusses the teaching work of the mathematics teacher in a historical-cultural perspective in the formative movement of the construction of the teacher's identity and professionalization. The purpose of this study is to elucidate the possible relationships that can be observed between the teaching work and the construction of the identity of the mathematics teacher in the proposal to present some determinations about: work - in a Marxian perspective - teaching work, identity and moving formation of the mathematics teacher. The text presents an analysis with elements of the historical-dialectic method that indicate possible relations between the professional and continuous formation that contribute to the constitution of the teaching identity of the subject that teaches and organizes the school knowledge in mathematics through its main activity.

Keywords: Teaching. Training in Movement. Professional Identity. Professor of Mathematics.

\footnotetext{
${ }^{1}$ Mestre em Ciências e Educação Matemática. Doutorando do Programa de Pós-graduação em Ciências e Educação Matemática da Universidade Federal de Goiás (UFG) Goiânia-GO/Brasil. Docente da SMEGoiânia/Colégio LASSALE/Faculdades Alfredo Nasser (UNIFAN). E-mail: brunosilvestre.prof@gmail.com
} 


\title{
TRABAJO DOCENTE: FORMACIÓN Y CONSTRUCCIÓN DE LA IDENTIDAD DEL PROFESOR DE MATEMÁTICAS
}

\begin{abstract}
RESUMEN: El presente ensayo discute el trabajo docente del profesor de matemáticas en una perspectiva histórico-cultural en el movimiento formativo de la construcción de la identidad y de la profesionalización de ese profesor. En el caso de los profesores de matemáticas, el profesor de matemáticas en la propuesta de presentar algunas determinaciones sobre: trabajo - en una perspectiva marxiana - trabajo docente, es un objetivo de elucidar las posibles relaciones que pueden ser observadas entre el trabajo docente y la construcción de la identidad del profesor de matemáticas en la propuesta de presentar algunas determinaciones sobre: trabajo - en una perspectiva marxiana - trabajo docente, identidad y formación en movimiento del profesor de matemáticas. El texto presenta un análisis con elementos del método histórico-dialéctico que indican posibles relaciones entre el profesional y la formación continua que contribuyen a la constitución de la identidad docente del sujeto que enseña y organiza el conocimiento escolar en matemáticas a través de su actividad principal.
\end{abstract}

Palabras clave: Trabajo Docente. Formación en Movimiento. Identidad Profesional. Profesor de Matemáticas.

O presente ensaio apresenta como problemática uma das categorias marxianas mais relevantes - o trabalho - com foco, neste estudo, no movimento do trabalho docente do professor que ensina matemática. Tem-se como questão: o que caracteriza o trabalho docente e como se constitui o processo de construção da identidade do professor de matemática? Para responder tal questionamento, objetiva-se elucidar as possíveis relações que podem ser observadas entre o trabalho docente e a construção da identidade do professor de matemática na proposta de apresentar algumas determinações sobre o trabalho, em uma perspectiva marxiana, o trabalho docente, a identidade e a formação em movimento do professor de matemática.

Na tentativa de responder à questão supracitada e alcançar o objetivo exposto, iniciam-se algumas reflexões teóricas sobre o conceito de trabalho, sobretudo o trabalho docente do professor de matemática, que sugere constantes aprendizagens, apropriações e objetivações, além de reflexões sobre sua própria ação (práxis), frente à grande diversidade do mundo atual em constantes transformações. Diante desse panorama, sobre o trabalho docente do professor de matemática, percebe-se que o trabalho docente está relacionado a inúmeros fatores e elementos, que dizem respeito à questão da identidade docente, também 
em constante movimento, que surge e ressurge ao longo da carreira profissional.

No movimento de compreender um pouco a realidade profissional do professor de matemática e as relações entre formação, identidade e trabalho docente realizou-se uma busca, no mês de maio deste ano, com o termo "identidade profissional do professor de matemática" no portal de periódicos da Coordenação de Aperfeiçoamento de Pessoal de Nível Superior (CAPES), encontrando no período compreendido entre 1998 a 2018 - que era o período em que a busca do site se limitava à pesquisa de produção textual -, um total de 211 trabalhos, entre estes: artigos científicos, dissertações e teses. Filtrada a busca para o último triênio, na tentativa de encontrar pesquisas mais recentes sobre a temática, ou seja, o que havia de produção mais atual, encontram-se 52 trabalhos, nos quais nenhum destes está em confluência com a perspectiva histórico-cultural aqui evidenciada. Desse modo, considera-se o ensaio relevante às pesquisas sobre essa temática no sentido de contribuir sobre o tema em questão.

O texto é organizado estruturalmente por meio de determinações sobre a categoria de trabalho e trabalho docente - entendido como Atividade mediada pela coletividade, que pode humanizar o homem, havendo nele a possibilidade de transformar-se e transformar a realidade, diferenciando-o dos demais - seguido de determinações sobre o processo de identidade e identidade docente e as possíveis relações com o trabalho do professor de matemática em seu movimento formativo, de trabalho e identidade em uma perspectiva histórico-cultural. Caracteriza-se o termo Atividade nas ideias da psicologia pedagógica soviética proposta por Leontiev (1983), entendida por alguns pesquisadores como Teoria da Atividade, na qual a Atividade é o que pode viabilizar ao homem tornar-se humano.

Segundo Leontiev (1983), a vida humana é um conjunto de atividades que vão substituindo umas às outras, e que, ao longo do desenvolvimento ontogenético/filogenético, há três atividades principais: jogo (atividade principal da criança), estudo (atividade principal dos sujeitos em idade escolar) e atividade de trabalho (na fase adulta do sujeito), a esta última atividade proposta por Leontiev (1983) dá-se maior evidência devido a sua percepção e determinação proposta por Marx (1988), que esclarece ser o que possibilita ao homem a superação dos status quo e as suas possíveis transformações. Desse modo, compreende-se o trabalho do professor e o seu processo de construção de identidade, neste ensaio, como um 
movimento humano que está impregnado de Atividade humana. Nessa perspectiva, apresentam-se, por meio de um diálogo teórico, reflexões sobre a construção da identidade do professor de matemática, com uma investigação do que é identidade e como ela é construída ao longo do tempo, sinalizando que ela está relacionada: à formação, à vivência, aos estudos, às pesquisas, aos lugares e aos espaços que o professor de matemática ocupa ao longo de sua vida, percebendo o processo de identidade como um movimento contínuo e em um constante vir-a-ser.

Finaliza-se o ensaio com uma análise sobre o conceito de trabalho docente do professor de matemática, compreendendo as relações entre a atividade de trabalho proposta pelo professor na organização do ensino, que é o objetivo principal dele ao: organizar, planejar, criar espaços, momentos e vivências para que seus estudantes se apropriem do conhecimento matemático historicamente elaborado pela humanidade - e o processo do professor na construção de sua identidade. A organização do ensino quanto: às escolhas, aos modos, aos processos, aos recursos e à forma didática que o professor desenvolve durante sua aula está condicionada a sua subjetividade, sua formação, sua identidade e sua profissionalidade que é mutável e passível de transformações constantes por meio de suas ações e suas reflexões sempre em movimento.

\section{O trabalho docente do professor que ensina matemática}

O que determina o trabalho docente do professor de matemática? Tal pergunta pode fomentar ao leitor outro questionamento fundamental: o que é trabalho? Sobretudo em uma sociedade que apresenta um sistema capitalista que promove substancialmente a alienação do trabalho e a produção visando o lucro e o acúmulo de capital de poucos privilegiados.

Sobre o que é trabalho, parte-se do pressuposto de que o homem constrói sua história e deixa suas marcas na sociedade por meio do seu trabalho - atividade principal dos sujeitos em fase adulta. O trabalho humano não alienado é sempre intencional, motivado por uma necessidade que pode humanizar o homem. É por meio do trabalho que é possível reproduzir as formas como a sociedade organizou a vida humana, e, em uma perspectiva marxiana, não somente reproduzir, mas, também, transformar as condições objetivas da vida humana.

Asbahr e Sanches (2006) definem o trabalho como: “[...] uma atividade libertadora da 
humanidade, pois tem como característica propiciar a transcendência da condição natural. Ao superar a natureza por meio do trabalho e por ser ético, ser de vontade, o homem constrói sua história" (p. 58-59). Nessa perspectiva, o trabalho é considerado como um processo que pode ocasionar a transformação, havendo uma superação de condição atual, que age intencionalmente nas necessidades objetivas para qualificar a vida de forma geral.

Para Mascarenhas (2002), o trabalho é a essência da hominidade, é sinônimo da onipotência humana, é o que pode nos distinguir dos outros animais, sendo possível somente na coletividade, partindo sempre de um modo de satisfazer uma necessidade, de modo a dar continuidade à própria existência. "O trabalho aparece ao homem como um meio para a satisfação de uma necessidade, a necessidade de manter a existência" (MASCARENHAS, 2002, p. 49). O trabalho é compreendido como uma atividade social, que pode manter, reproduzir e transformar a existência do homem, consequentemente, mantém a existência da sociedade, dando a ideia de coletividade. Desse pressuposto, todo trabalho não alienado é produção social e coletiva, até mesmo o trabalho individual que, aparentemente, não parece ser coletivo, particularmente, já foi ou é fruto de alguma produção anterior realizada pela humanidade, como apresentam Asbahr e Sanches (2006).

Compreende-se o trabalho por meio de três elementos principais, assim como proposto por Asbahr e Sanches (2006).

- O objeto de trabalho: o que se tem e será transformado;

- O instrumento de trabalho: mediação entre homem e objeto de trabalho;

- A força de trabalho.

Pensando no trabalho docente, os dois primeiros elementos estão relacionados às condições objetivas do trabalho necessárias para produzir. O último elemento está relacionado às condições subjetivas, ou seja, a subjetividade do próprio homem.

Na docência, a atividade principal do professor é ensinar, cujo objeto do trabalho é o ensino dos conceitos historicamente elaborados pela humanidade, relacionados com os conteúdos destinados à aprendizagem dos estudantes. Os instrumentos de trabalho, utilizados no trabalho docente, podem ser diversos, considerando a utilização de ferramentas ou recursos de ensino, como: jogos, tecnologias, materiais concretos, situações problemas, tarefas de investigação, entre outros, utilizados para que os estudantes se apropriem do 
conhecimento. Já a força de trabalho para o professor relaciona-se com a sua interação subjetiva estabelecida entre o próprio professor, o conhecimento e os estudantes, e está relacionada ao modo como o professor organiza metodologicamente o ensino para que os sujeitos se apropriem do conhecimento teórico, como apresentam Anastasiou e Alves (2006) quanto às várias estratégias e aos vários processos de ensinagem, e sendo objeto constante de estudo da didática.

O foco deste estudo está no terceiro elemento supracitado: "força de trabalho". O modo metodológico que o professor irá organizar o ensino está intimamente relacionado a sua subjetividade, a sua formação específica de área de conhecimento, a sua formação didática e, sobretudo, as suas ações e reflexões em organizar o ensino, que, por sua vez, está relacionado, também, a sua identidade e personalidade, conforme é apresentado por Martins (2015). Os fatores subjetivos da atividade docente relacionada à força de trabalho do professor estão condicionados a sua vivência e experiência na coletividade, gerando, então, sua singularidade, concordando com as ideias apresentadas por Vigotski (2010) com seu conceito de movimento formativo interpsíquico para o intrapsíquico, que ocasiona não somente as transformações psicológicas do social para o individual, mas a singularidade como sujeito humano partindo da totalidade.

Vigotski (2010) apresenta o meio, ou seja, o mundo circundante como um importante elemento à constituição da personalidade do sujeito que está condicionado à dinâmica e às contradições da vivência.

\begin{abstract}
A vivência é uma unidade na qual, por um lado, de modo indivisível, o meio, aquilo que se vivencia está representado - a vivência sempre se liga àquilo que está localizado fora da pessoa - e, por outro lado, está representado como eu vivencio isso, ou seja, todas as particularidades da personalidade $\mathrm{e}$ todas as particularidades do meio são apresentadas na vivência, tanto aquilo que é retirado do meio, todos os elementos que possuem relação com dada personalidade, como aquilo que é retirado da personalidade, todos os traços de seu caráter, traços constitutivos que possuem relação com dado acontecimento. Dessa forma, na vivência, nós sempre lidamos com a união indivisível das particularidades da personalidade e das particularidades da situação representada na vivência (VIGOTSKI, 2010, p. 686).
\end{abstract}

Nesse sentido, a vivência coletiva social é um elemento que vai possibilitar a construção da personalidade do sujeito e poderá ser um dos elementos que viabilizam a 
construção da identidade do trabalho docente. Mascarenhas (2002) contribui propondo que é por meio do trabalho nas relações com o outro e com a natureza que o homem encontra em si mesmo sua singularidade, tendo a capacidade de se formar e se desenvolver na totalidade.

O homem encontra sua singularidade, diferenciando-se dos demais, nas pequenas unidades particulares que compõem sua totalidade, uma de suas unidades é a sua capacidade de se formar/desenvolver. A formação e/ou o desenvolvimento é atividade exercida pelo coletivo, construída por meio das relações que o ser humano apresenta com a natureza e a sociedade, logo, sem o homem não é possível educar, conforme apresenta Moretti (2010). A humanidade está em um constante aprender: os filhos aprendem com os pais, o empregado aprende com seus superiores e/ou colegas de trabalho, na fila de um banco o sujeito pode aprender a utilizar rapidamente algum aparelho/caixa eletrônico ao observar alguém que esteja na sua frente etc.

Em todos os exemplos citados, percebe-se que a aprendizagem está em consonância com a interação com o outro ou com a coletividade, assim como é defendida por Bussmann e Abbud (2002) "[...] a tarefa docente não se limita a fornecer informações, tem uma dimensão formativa que só é possível pela interação entre pessoas" (p. 134). A sociedade caracterizada na singularidade pela atuação do homem está em constante movimento de aprender e temse um profissional específico para mediar e subsidiar essa aprendizagem: o professor. Por meio do trabalho docente, o professor exerce a função de ensinar conteúdos teóricos e formar politicamente seus educandos, tornando-os críticos de modo a terem uma visão geral da totalidade do que a humanidade produz e/ou já produziu partindo de suas necessidades naturais, culturais e sociais, compreendendo suas especificidades, conservando-as (reproduzindo-as) e, se, possível transformando-as.

Quando se trata da tarefa educativa é preciso lembrar que essa é, em princípio, uma atividade exercida pelo conjunto dos membros de uma sociedade no seu cotidiano. Todos se educam e são educados nos diferentes tempos e espaços da vida social, mas o professor é aquele que tem por profissão, ou seja, por função social específica e especializada, realizar parcela significativa da atividade educativa que a sociedade considera relevante para sua conservação e transformação (BUSSMANN; ABBUD, 2002, p. 135)

Ser professor, assumir a profissão docente pode ser uma tarefa complexa na 
sociedade, pois, além de dominar os conhecimentos teóricos específicos, o trabalho docente exige a dinâmica em conhecer os processos que tal conhecimento teórico passou ao longo da história da humanidade, verificando-se a necessidade em compreendê-lo no momento atual, ao agir de forma intencional, ao motivar e ao formar criticamente seu produto final, que se apresenta como um ser humano igual a ele, pressupondo a interação - professor e aluno - na qual o professor ensina e ao ensinar também aprende. Aprende como mediar o conhecimento teórico, incentivando e criando uma necessidade no educando, por meio das múltiplas interações subjetivas em compreender o que está sendo proposto.

O saber teórico - conhecimento específico - do professor não é suficiente para ensinar e criar necessidades de aprender em seus educandos. O professor tem a intencionalidade de compreender os conteúdos e dar sentidos ao conhecimento, para isto é necessário que - ele organize adequadamente o ensino, sabendo o conhecimento teórico e também sabendo ensinar, como apresentam Bussmann e Abbud (2002, p. 137), “Assim, saber e saber ensinar podem ser consideradas duas dimensões do processo de educar que caracteriza o trabalho do professor". Outra autora, Roldão (2007), contribui para o diálogo abordando sobre os saberes que o professor deveria possuir para exercer o ofício de ensinar, está entre o "professar um saber", que está relacionado ao saber específico, propriamente o conhecimento teórico, e o "fazer aprender alguma coisa a alguém", que está relacionado ao modo de ensinar.

O trabalho do professor em ensinar o conhecimento teórico, sendo este um dos objetivos do trabalho docente, precisa estar na perspectiva de que o estudante é objeto do seu trabalho, e não somente objeto, mas, também, sujeito de sua própria aprendizagem. Assim como apresentam Asbahr e Sanches (2006, p. 68), “O aluno não é, portanto, mero consumidor da aula ou objeto de trabalho do professor, mas é principalmente sujeito da atividade de ensino". Para que o educando seja sujeito de sua própria aprendizagem, é necessário que o professor crie meios e viabilize situações de ensino para que ele tenha motivos para se apropriar dos conceitos propostos, pois o aluno motivado pode melhor interagir com o professor, otimizando seu aprendizado e, consequentemente, otimizando o ensino do professor, conforme descreve Leontiev (2017).

Especificamente ao trabalho do professor de matemática, faz-se necessário, assim como característica principal do trabalho docente, saber e saber ensinar. O saber do professor 
de matemática está intrínseco ao conhecimento teórico específico no que diz respeito à matemática. Exige-se desse profissional, portanto, a apropriação dos conceitos que regem essa área de conhecimento e as formas de organizar o ensino em confluência de tais conceitos.

O termo apropriar significa não apenas compreender o conceito, mas conhecer sua origem, sua história, o modo como foi construído, satisfazendo uma necessidade de um determinado povo em uma determinada época. Segundo Leontiev (1983 apud MORETTI, 2011), "apropriar-se de um conceito matemático implica conhecer não apenas sua definição formal e saber operar com ele, mas também atribuir sentido pessoal as suas significações sociais" (p. 386). O conhecimento matemático foi objetivado pela produção humana por meio do trabalho e está cristalizado na cultura por meio das significações sociais. Exemplos de significações sociais são os conceitos matemáticos, que, se apropriados pelos sujeitos, estão intimamente relacionados à atribuição de sentido pelos sujeitos que estão se apropriando dessas significações. Cabe ao professor que ensina matemática essa constante apropriação do conhecimento matemático e didático - saber ensinar.

Para Duarte (2013), a apropriação é uma condição intrinsecamente humana. Um exemplo de apropriação humana da natureza é a transformação, movida por necessidades objetivas humanas, de objetos naturais em ferramentas humanas, que, por sua vez, são apropriadas na sua forma essencial e natural e são objetivadas quando transformadas em ferramentas para uso que não a sua função original.

[...] O que possibilita o desenvolvimento histórico é justamente o fato de que a apropriação de um objeto - transformando-o em instrumento, pela objetivação da atividade humana nesse objeto, inserindo-o na atividade social - gera, na atividade e na consciência dos seres humanos, novas necessidades e novas forças, faculdades e capacidades. Ou seja, a relação entre objetivação e apropriação na incorporação de forças naturais à atividade social gera a necessidade de novas apropriações e novas objetivações (DUARTE, 2013, p. 32).

A atividade humana é um constante apropriar-se e objetivar-se dos objetos, das ferramentas e das significações sociais presentes na sociedade, e, ao apropriar e objetivar, nesse movimento ininterrupto, os sujeitos se transformam e transformam o modo de vida e de produção da sociedade como um todo (DUARTE, 2013). Pensando no trabalho docente em matemática, durante os processos formativos constituídos no decorrer da vida do professor 
de matemática, tanto nos conhecimentos teóricos específicos quanto nos conhecimentos didático-metodológicos relacionados às apropriações desses conhecimentos, que são significações sociais, que, futuramente, podem ser objetivadas de acordo com a sensibilidade, a observação e a reflexão do professor, pode-se traduzir a essa apropriação e objetivação em sua prática docente, ou seja, em sua profissionalidade.

Para além do saber do professor de matemática, no exercício da função docente, é necessário saber ensinar. Para saber ensinar os conceitos matemáticos outrora apropriados, é preciso, sobretudo, tornar-se professor em um movimento contínuo de vir-a-ser. Tornar-se professor significa poder transformar a realidade dos educandos, mediando o processo de aprendizagem de modo a criar necessidades de aprender em seus alunos. Segundo Moretti (2011), tornar-se professor de matemática implica mediar o processo de aprendizagem, articulando teoria e prática na práxis pedagógica.

Para Bussmann e Abbud (2002), tornar-se professor exige assumir uma postura de pesquisador em todos os âmbitos de sua formação, quer dizer, tornar-se professor transcende expectativas simples, tal movimento exige uma transformação complexa que diz respeito à identidade do sujeito que escolhe a profissão docente. Nos estudos de Silvestre (2016), compreender o trabalho docente exige uma atividade de estudo intencional sobre como organizar a atividade de ensino desde a formação profissional inicial à formação continuada ininterrupta e em constante movimento. Para o autor, desde a formação profissional inicial deve-se ter uma preocupação e um cuidado sobre qual profissional a instituição de ensino superior pretende formar.

Segundo Silvestre (2016),

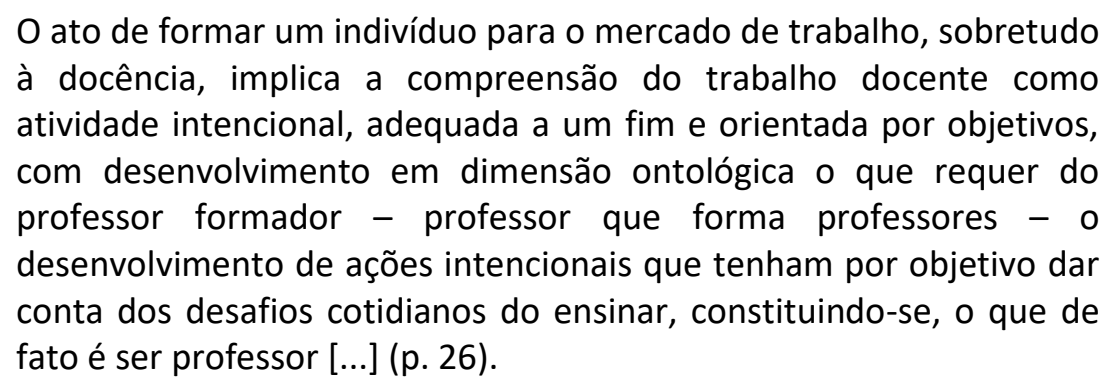

Orienta-se por objetivos intencionais durante a formação profissional inicial a formação do futuro professor, para que exerça sua docência de modo a superar a profissionalidade hegemônica existente que somente reproduz o modelo vigente. Tornar-se 
professor exige uma constante reflexão sobre essa atividade laboral, que está relacionada aos aspectos formativos, específicos e didáticos e, também, ao modo como o sujeito vai atribuindo sentido a sua docência por meio de suas vivências e experiências ao longo de sua realidade objetiva de vida. Desse modo, o que determina o trabalho docente do professor de matemática é o modo e/ou os processos pelos quais este profissional organiza o ensino, dando possibilidades para que os estudantes se apropriem dos conhecimentos historicamente organizados pela humanidade, sobretudo os conhecimentos matemáticos produzidos pelo fazer e pensar humano, tendo a possibilidade de atribuir sentidos a este conhecimento. No entanto, para organizar o ensino em uma perspectiva em que o estudante seja autor do seu conhecimento e o professor atue como mediador, por meio de sua atividade principal trabalho - mais especificamente, o trabalho de ensinar, o professor deve estar em um constante processo de apropriação e objetivação de seu trabalho, viabilizando a sua própria transformação e a transformação do trabalho docente.

O professor vai se constituindo enquanto sujeito que organiza intencionalmente o conhecimento matemático por meio dos saberes relacionados ao seu trabalho, que, por sua vez, estão relacionados à formação específica de área de conhecimento - matemática - e à forma, aos modos e aos processos de como organizar o ensino, ligados ao campo da didática, tomando como tarefas da atividade docente as ações intencionais que viabilizem a apropriação do conhecimento matemático pelos estudantes, tendo o professor constantes ações de organização, reflexão e novas ações sobre seu trabalho de ensinar. Esse processo de organizar intencionalmente o ensino não é uma tarefa trivial e está relacionado aos elementos construtivos aos quais o professor vivencia ou já vivenciou quanto aos aspectos: sociais, políticos, econômicos, visão de mundo, organização das ideias, elementos formativos adquiridos antes, durante e após a formação profissional inicial, elucidando a constituição da identidade do professor ao longo deste processo.

Mas de que modo acontece tal transformação elucidada na perspectiva marxiana e como se dá o processo de construção da identidade do professor de matemática? Na próxima seção, serão elencados alguns aspectos sobre o processo de tornar-se professor de matemática e o processo de constituição da identidade docente, especificamente do professor como sujeito em constantes transformações. 


\section{A construção da identidade do professor de matemática}

Para determinar o conceito de identidade docente, deve-se compreender, primeiramente, o que é identidade, compreendendo-a como totalidade para então avançar para suas especificidades quanto ao trabalho docente. Para tal, concorda-se com as ideias propostas por Ciampa (2001), demonstrando a identidade como um processo subjetivo complexo em constante constituição.

Nos estudos apontados por Ciampa (2001), sugerem-se algumas perguntas que elucidam aspectos da identidade, tais como: Quem é você? O questionamento conduz o leitor a voltar-se reflexivamente a si e questionar. Quem sou eu? Aparentemente simples, mas essencialmente complexo, tal questionamento torna-se, talvez, difícil de responder.

A questão "Quem sou eu?" Pode originar várias respostas que indicam um pragmatismo quanto ao sexo, à origem, à opção sexual, à idade, à formação cultural e/ou acadêmica, ao status profissional, às preferências musicais e uma gama de outras coisas que podem ser agregadas. Tais determinações objetivas podem compor elementos da identidade de um indivíduo. Ciampa (2001, p. 72) apresenta que: “[...] é do contexto histórico e social em que o homem vive que decorrem suas determinações e, consequentemente, emergem as possibilidades ou impossibilidades, os modos e as alternativas da identidade". Observa-se que a identidade é construída por meio das interações com o contexto histórico social do sujeito. Torna-se relevante acrescentar que a identidade pode estar em constante transformação, pois o contexto social está sempre em movimento, assim como o sujeito que faz parte desse contexto. Identidade é processo e é transformação que vai se constituindo, criando, recriando, e transformando-se em um constante movimento.

Ciampa (2001) apresenta a identidade como movimento, sendo desenvolvimento do concreto, no mesmo instante em que se é "um", particular e individual, somos "um outro", no qual espelhamos nosso particular e individual em outrem, para que então nos tornemos quem realmente somos, em outras palavras, adquirimos nossa identidade nesse movimento constante por meio da vivência. 
Identidade é movimento, é desenvolvimento do concreto.

Identidade é metamorfose.

É sermos o Um e um Outro, para que cheguemos a ser Um, numa infindável transformação (CIAMPA, 2001, p. 74).

A identidade profissional, estando em movimento e constante transformação, na interação individual com o contexto histórico social, passa também por aspectos culturais e políticos que se inserem à atividade do professor e à especificidade de sua profissão, como apresentado por Gama e Fiorentini (2008).

Após a formação inicial, geralmente em licenciatura em matemática ou em outra área do saber, que preparou o sujeito para o trabalho docente para desenvolver o ensino de matemática, apresentaram-se disciplinas específicas da formação, como é o caso da matemática e das outras específicas relacionadas ao processo de ensino e aprendizagem, ou seja, as didáticas. O indivíduo que obteve uma formação inicial profissional para o trabalho docente depara-se com o que foi desenvolvido na universidade, teoria, com a prática ao ingressar-se pela primeira vez em um ambiente educativo como docente, exercendo seu ofício no qual esteve outrora em formação.

Quanto a esse primeiro momento do trabalho docente no ambiente educativo, Gama e Fiorentini (2008) apresentam dois aspectos que podem constituir a identidade do professor de matemática. O primeiro aspecto está associado a um "choque de realidade", estando relacionado às situações complexas que o professor iniciante enfrentará, como: dificuldades de relacionamento com a comunidade escolar, dificuldades em ensinar ou, até mesmo, dificuldades de utilizar determinados materiais didáticos. O segundo aspecto está relacionado ao sentimento de "descoberta" de seu trabalho, expressando o sentimento de entusiasmo pela profissão docente, marcado pela responsabilidade de exercer o trabalho como professor. Os dois aspectos, agindo dialeticamente, marcam a identidade do professor iniciante e direcionam a construção e a reconstrução da identidade dos professores já veteranos.

Retomando o nosso objetivo principal, de compreender especificamente a identidade do professor de matemática, observa-se que a identidade de se tornar professor é construída em movimento no contexto histórico e social, a partir do momento em que o sujeito interage com o trabalho docente específico de ministrar a disciplina de matemática. $\mathrm{O}$ trabalho desse professor acontece na coletividade, assim como apresentam Brzezinski (2002), Gama e 
Fiorentini (2008), Makarenko (1977), Moura (2003) e Moretti (2011).

Gama e Fiorentini (2008) entendem a identidade do professor de matemática como múltiplas identidades, pois os conflitos gerados entre o professor individual e os múltiplos fatores do ambiente de ensino, acontecendo sempre na coletividade, podem ocasionar diferentes identidades em diferentes momentos. "A construção e o compartilhamento de aprendizagens coletivas, nas diferentes comunidades de prática que o professor participa, parecem influenciar os processos de mudanças e a própria constituição de suas múltiplas identidades" (p. 33). Percebe-se que, na proposta dos autores supracitados, a identidade docente está em confluência com as relações que o docente estabelece com os espaços e com as vivências nos quais ele realiza seu trabalho docente, nos seus momentos formativos e na sua coletividade com os pares e com outros professores, além das relações estabelecidas em cada cultura escolar, sintetizando a identidade docente como um movimento de múltiplas determinações objetivadas de acordo com a realidade vivida pelo professor.

A identidade docente profissional está reafirmada de acordo com a vivência e as experiências desenvolvidas na coletividade, conforme apresenta Brzezinski (2002).

A identidade construída pode ser pessoal ou coletiva. A primeira é configurada pela história e experiência pessoal e implica um sentimento de unidade, originalidade e continuidade, enquanto que a segunda é construção social que se processa no interior dos grupos e das categorias que estruturam a sociedade e que conferem à pessoa um papel e um status social. A identidade profissional configura-se como identidade coletiva (p. 8).

Segundo os autores elencados até o momento, o espaço social, ou o ambiente coletivo é de extrema importância para que se adquira, construa e reconstrua a identidade de professor. Para Moura (2003), o movimento de tornar-se professor, especificamente ao profissional que leciona matemática, construir sua identidade como docente e construir a sua profissionalidade se concentra em dois componentes: "sua história de formação acadêmica, na qual se incluem suas motivações e o coletivo escolar ao qual passa a pertencer" (p. 138).

As relações de interação que o professor de matemática terá no ambiente escolar com o coletivo de sujeitos que estão presentes em seu trabalho, aliadas aos valores e a todo o conhecimento teórico apropriado durante sua trajetória acadêmica, formarão sua identidade, que, por sua vez, estará em constante transformação, em um movimento contínuo. Estando 
a identidade do professor de matemática em movimento de transformação, é importante compreender esse processo de continuidade, tanto de sua identidade, quanto da própria profissão docente, que tem por objetivo maior fazer com que os educandos apropriem os conhecimentos teóricos produzidos ao longo da história da humanidade, partindo de suas necessidades específicas para organizar melhor a vida coletiva e individual, que, ao longo do processo histórico, qualificou e transformou toda a sociedade por meio do trabalho. No próximo tópico, procura-se relacionar o trabalho docente e a identidade do professor de matemática elencando alguns fatores supracitados, como: vivência, formação, trabalho, personalidade, apropriação, objetivação e identidade, na perspectiva de construir uma determinação síntese destes aspectos para caracterizar o trabalho docente do professor de matemática.

\section{O professor de matemática, sua identidade e profissionalidade em movimento}

O trabalho docente, de maneira geral, está condicionado à formação teórica do saber e ao modo de ensinar tal saber. No caso específico do conhecimento matemático, esse condicionamento não é diferente, é necessário apropriar-se do conhecimento matemático e saber operar com ele em suas diferentes dimensões. Muito mais que apropriar-se do conhecimento matemático, é extremamente interessante que o professor de matemática conheça os reais motivos que levaram a humanidade a construir determinado conceito ou conhecimento matemático dentro de uma perspectiva histórica, de modo a criar em seus alunos a necessidade de compreender tal conhecimento.

Uma pesquisadora brasileira séria que desenvolve pesquisas nessa perspectiva em desenvolver situações de ensino que remontam às necessidades humanas da construção do conceito produzido ao longo da história da humanidade é Sousa (2014), dentro da perspectiva do lógico-histórico e do ensino de matemática. Esse movimento de apropriação do conhecimento matemático acontecerá em um primeiro momento na formação inicial do professor e, posteriormente, em sua formação continuada, sempre interagindo na coletividade de seus locais de trabalho.

Para Moura (2003), a formação inicial é muito importante para as ações e as atitudes iniciais que o professor desempenhará na primeira escola que irá recebê-lo, sendo resultado 
de suas concepções sobre o que ele entende sobre o seu papel de professor. O que anteriormente ele concebia como aprendizagem, agora se torna um trabalho, o trabalho de ensinar, ou seja, criar uma necessidade de aprender em seus educandos.

[...] a formação inicial do professor eleva o seu nível de compreensão sobre os sistemas escolares além daquele adquirido quando apenas recebia os serviços da escola. Como aluno, esperava que a escola o acolhesse, que lhe permitisse aprender. Sua atividade era de aprendiz. Como professor, numa atividade profissional, sua formação inicial é o seu referencial para interagir com a cultura pedagógica da escola. São suas potencialidades iniciais junto à cultura pedagógica da escola que podem permitir o desenvolvimento do ensino de um nível para outro. Nessa nova qualidade de sujeito/professor, sua atividade principal é ensinar (MOURA, 2003, p. 133).

A atividade principal do professor de matemática é ensinar. Ensinar não somente no sentido de transmitir conhecimento para os educandos, mas, sim, dar sentido ao que se ensina, motivando os alunos em um constante movimento de apropriação dos conceitos matemáticos: algébricos, geométricos, aritméticos, estatísticos etc., atribuindo-Ihes sentido e compreendendo o porquê de estudar tais conceitos. Segundo Roldão (2007), ensinar significa fazer aprender alguma coisa a alguém, neste caso os conhecimentos matemáticos presentes nos currículos escolares. O melhor lugar para atingir o objetivo principal do professor em ensinar é justamente na escola, assim como apresentado por Moura (2003, p. 129), "Partimos da consideração de que a educação formal continua sendo necessária e que o lugar privilegiado para fazê-la continua sendo a escola como um espaço que visa à concretização das intenções educativas".

Para que o ensino aconteça efetivamente, o professor deve agir de maneira intencional, mediando o processo de ensino nos educandos, fomentando a criação de uma necessidade de aprender. Moretti (2011, p. 387) foca-se no ensino e na aprendizagem de matemática, o professor agindo de maneira intencional pode "lançar mão de problemas desencadeadores ou situações problema que tenham como essência a necessidade que levou a humanidade à construção do conceito".

Para Moretti (2011), quando se utiliza intencionalmente de situações desencadeadoras de aprendizagem ou de situações problemas que levaram a humanidade à construção dos conceitos matemáticos, o professor aprende continuamente o processo da 
docência em matemática, estando este profissional em constante aprendizagem ao compreender como melhor criar tais necessidades nos educandos. O trabalho docente está sempre em movimento para aprender a melhor maneira de ensinar, lançando mão de metodologias e de estratégias que criem necessidades de aprender nos alunos. No entanto, só é possível ensinar aquilo que realmente foi apropriado, dando maior sentido ao trabalho docente.

Moura (2003) defende que a formação deve ser continuada, construída continuamente na prática docente, visando um trabalho de coletividade. O trabalho em conjunto com outrem torna esse processo de aprendizagem muito mais viável, tendo o professor um importante papel em mediar o conhecimento. Ao agir de maneira intencional, até pelo fato de a identidade ser construída na interação social, o ensino se torna mais significativo quando há troca de informações e de conhecimento com os demais professores e com o próprio ambiente escolar.

Compreender o trabalho como atividade humana, transformadora, que apresenta como motivo individual e coletivo do sujeito em transformar a realidade é essencial para estabelecer relações com o trabalho docente, especificamente o trabalho do professor de matemática, que em essência deve oferecer um ensino transformador aos seus alunos, levando-os à apropriação dos conceitos matemáticos. O que caracteriza o trabalho docente, seja ele específico do professor de matemática ou não, é o saber teórico do conhecimento que se deseja ensinar e o modo como acontece este ensino, ou seja, o saber ensinar, que, por sua vez, está impregnado de atividade humana histórica e cultural.

\section{Algumas considerações sobre o trabalho docente e a identidade do professor de matemática}

Para a organização de uma síntese que caracteriza o trabalho docente do professor de matemática, foram construídas ao longo do texto algumas determinações sobre este fenômeno que está presente na realidade objetiva social e cultural escolar. Utiliza-se, desse modo, o conceito marxiano de análise, partindo do método histórico dialético, que procura perceber o processo por meio das contradições e das determinações que conjecturam e expressam a totalidade do objeto de estudo. Para uso do método, apoia-se no trabalho de Gil 
de San Vicente (2007) quanto às categorias da dialética, que afirma que estão presentes dos conceitos de subjetividade por meio do pensamento humano, da produção humana material e imaterial, e das contradições que permitem compreender a essência dos fenômenos.

Destarte, após apresentar teoricamente alguns elementos sobre o trabalho, trabalho docente, processos de formação da identidade e formação do professor de matemática, parte-se de uma análise do processo tendo a dialética como elemento e princípio de análise, pois as determinações elencadas ao longo do texto são determinações materiais concretas que estão relacionadas à constituição do trabalho docente, processos de construção da identidade por meio da vivência estabelecidos pelas atividades principais humanas, formação profissional e práxis pedagógica. Elas, por sua vez, estão imbricadas às questões subjetivas relacionadas à identidade e ao fazer humano, e que podem subsidiar transformações pessoais e societárias quando pensadas intencionalmente.

Determina-se, então, que o professor de matemática, para desenvolver seu trabalho docente, produz meios e modos de criar necessidades que motivem os estudantes a apropriarem e objetivarem os conceitos matemáticos, tendo como fundamento os motivos que levaram a humanidade a criar tais conceitos. No entanto, esse trabalho só é possível se o professor agir de maneira intencional, norteado por objetivos, utilizando-se de situações desencadeadoras de aprendizagem ou de situações problemas, com a intenção de dar sentido ao processo de ensino.

Para dar sentido ao processo de ensino aos educandos, o professor deverá estar em constante aprendizagem, em um constante processo e movimento de vir-a-ser, refletindo sobre sua prática e tentando a todo tempo uma superação de sua atividade de ensino, realizada por meio do trabalho. Deverá, também, superar a atividade de estudo dos estudantes quanto à reprodução de conhecimento matemático para a produção do conhecimento matemático, descobrindo a melhor forma de realizar seu trabalho, seja se formando melhor teoricamente ou compreendendo a melhor maneira de criar necessidades e motivos nos estudantes para que estes tenham a possibilidade de apropriar-se dos conhecimentos e dos conceitos matemáticos produzidos ao longo da história da humanidade.

Toda essa complexidade e dinâmica do trabalho docente desenvolvidas pelo professor de matemática passam por questões subjetivas acerca de sua identidade, que é construída 
em movimento contínuo principalmente nas relações histórico-sociais e na coletividade, seja ela em seu local de trabalho ou meio cultural que ele traz consigo de sua formação inicial/continuada e, sobretudo, de suas vivências teóricas e práticas. Caracteriza-se o trabalho docente do professor de matemática como atividade humana principal, trabalho, que tem como objeto o ensino e caracteriza-se, também, como um processo em transformações constantes, que permeiam a sua formação teórica e prática, na qual realiza ações de práxis e reflexões sobre essa ação, que tem a intenção maior de criar necessidades e motivos para que seus estudantes se apropriem dos conhecimentos matemáticos historicamente desenvolvidos pela humanidade.

No entanto, esses processos de transformações estão relacionados intrinsecamente sobre quem é, e de quem se trata esse profissional, relacionado a sua vivência histórica e permeado a sua identidade em que se expressa a sua personalidade, que, por sua vez, é constituída dialeticamente nas relações sociais e no convívio por meio de suas experiências formativas. Desse modo, a construção da identidade do professor de matemática pode ser pensada como movimento constante, dialético e mutável, pois, à medida que o sujeito vai se apropriando e objetivando de elementos de sua vivência, ele vai adquirindo formas novas de organizar e atuar frente à realidade de sua própria vida e realidade profissional. 


\section{Referências}

ANASTASIOU, L. G. C.; ALVES, L. P. (org.). Processos de ensinagem na universidade: pressupostos para as estratégias de trabalho em aula. 6. ed. Joinville-SC: UNIVILLE, 2006. ASBAHR, F. S. F.; SANCHES, Y. C. S. Transformação social: uma possibilidade da educação escolar? In: PARO, V. H. (org.). A teoria do valor em Marx e a educação. São Paulo: Cortez, 2006.

BRZEZINSKI, I. Profissão professor: identidade e profissionalização docente. In: (org.). Profissão professor: identidade e profissionalização docente. Brasília: Plano Editora, 2002. p. 7-19.

BUSSMANN, A. C.; ABBUD, M. L. M. Trabalho docente. In: BRZEZINSKI, Iria (org.). Profissão Professor: identidade e profissionalização docente. Brasília: Plano Editora, 2002. p. 133-144. CIAMPA, A. Identidade. In: LANE, S. (org.). Psicologia social - o homem em movimento. São Paulo: Brasiliense, 2001. p. 58-75.

DUARTE, N. A individualidade para si: contribuição a uma teoria histórico-crítica da formação do indivíduo. 3. ed. Revisada. Campinas-SP: Autores Associados, 2013.

GAMA, R. P.; FIORENTINI, D. Identidade de professores iniciantes de matemática que participam de grupos colaborativos. Horizontes, v. 26, n. 2, p. 31 - 43, jul./dez. 2008.

LEONTIEV, A. N. Actividad, consciencia, personalidad. Habana: Editorial Pueblo y Educación, 1983.

As necessidades e os motivos da atividade. In: LONGAREZZI, A. M.; PUENTES, R. V. (org.). Ensino Desenvolvimental: Antologia. Livro I. Uberlândia/MG: EDUFU, 2017. p. 39-58. MAKARENKO, A. S. La colectividad y la educación de la personalidad. Moscú: Progreso, 1977.

MARTINS, L. M. A formação social da personalidade do professor: um enfoque vigotskiano. 2. ed. Campinas-SP: Autores Associados, 2015.

MARX, K. O Capital. Vol. 2. 3. ed. São Paulo: Nova Cultural, 1988.

MASCARENHAS, A. C. B. O trabalho e a identidade política da classe trabalhadora. Goiânia: Alternativa, 2002.

MORETTI, V. D. A Formação Docente na Perspectiva Histórico-Cultural: em busca da superação da competência individual. Psicologia Política, v. 10, n. 20, p. 345-361, jul./dez. 2010.

A articulação entre a formação inicial e continuada de professores que ensinam matemática: o caso da Residência Pedagógica da Unifesp. Educação, Porto Alegre, v. 34, n. 3, p. 385-390, set/dez. 2011.

MOURA, M. O. O educador matemático na coletividade da formação. In: TALIBANI, E. F. A.; CHAVES, S. M. (org.). Concepções e práticas em formação de professores: diferentes olhares. Rio de Janeiro: DP\&A, 2003. p. 129-145. 
ROLDÃO, M. C. Formação docente: natureza e construção do conhecimento profissional. Revista Brasileira de Educação, v. 12, n. 34, p. 94-103, jan./abr. 2007.

SOUSA, M. C. O Ensino de Matemática da Educação Básica na Perspectiva Lógico-Histórica. Perspectivas da Educação Matemática, v. 7, n. 13, p. 60-83. UFMS, Mato Grosso do Sul, 2014. Disponível em: $\leq$ http://seer.ufms.br/index.php/pedmat/article/view/490>. Acesso em: 30 dez. 2018.

SILVESTRE, B. S. A formação do professor de matemática: o jogo como recurso de ensino. Dissertação (Mestrado em Educação em Ciências e Matemática) - Universidade Federal de Goiás, Goiânia, 2016.

GIL DE SAN VICENTE, I. La dialéctica como arma, método, concepción y arte. 2007. Disponível em: <http://www.rebelion.org/noticia.php?id=55787>. Acesso em: 30 dez. 2018. VIGOTSKI, V. L. Quarta aula: a questão do meio na pedologia. Tradução Regina Pillegi Vinha. Revista Psicologia, v. 21, n. 4, p. 681-701, 2010.

Recebido em: 15/05/2018 Aprovado em: 31/07/2018 